2008-402-0313

\title{
Spacesuit Water Membrane Evaporator Development for Lunar
} Missions

\author{
Matt R. Vogel, Keith Peterson, Felipe Zapata III, Paul Dillon \\ ESCG-Jacobs-Svedrup, Houston TX \\ Luis A. Trevino \\ NASA Johnson Space Center, Houston TX
}

Copyright $\odot$ SAE International

\begin{abstract}
For future lunar extra-vehicular activities (EVA), one method under consideration for rejecting crew and electronics heat involves evaporating water through a hydrophobic, porous Teflon ${ }^{\circledR}$ membrane. A Spacesuit Water Membrane Evaporator (SWME) prototype using the Teflon ${ }^{\circledR}$ membrane was tested successfully by Ungar and Thomas (2001) with predicted performance matching test data well [1]. The above referenced work laid the foundation for the design of the SWME development unit, which is being considered for service in the Constellation System Spacesuit Element (CSSE) Portable Life Support System (PLSS). Multiple PLSS SWME configurations were considered on the basis of thermal performance, mass, volume, and performance and manufacturing risk. All configurations were a variation of an alternating concentric water and vapor channel configuration or a stack of alternating rectangular water and vapor channels. Supporting thermal performance trades mapped maximum SWME heat rejection as a function of water channel thickness, vapor channel thickness, channel length, number of water channels, porosity of the membrane structural support, and backpressure valve throat area. Preliminary designs of each configuration were developed to determine total mass and volume as well as to understand manufacturing issues. Review of configurations led to the selection of a concentric annulus configuration that meets the requirements of 800 watts (W) of heat rejection. Detailed design of the SWME development unit will be followed by fabrication of a prototype test unit, with thermal testing expected to start in 2008.
\end{abstract}

\section{INTRODUCTION}

Previous work demonstrated the feasibility of cooling water flowing through a loop by evaporating water through a hydrophobic, porous Teflon $\AA$ membrane. The Teflon $®$ membrane SWME prototype tested by Ungar and Thomas consisted of a single circular annulus water channel bounded by two annulus vapor channels, of which a vacuum was maintained [1]. Thermal testing of this prototype measured up to $480 \mathrm{~W}$ of heat removal from water flowing at $90 \mathrm{~kg} / \mathrm{hr}$.

An effort was undertaken to advance the Teflon $®$ membrane evaporator technology by designing, building, and testing a SWME that would meet selected design and performance requirements of the new National Aeronautics and Space Administration (NASA) spacesuit. Key requirements included removing $810 \mathrm{~W}$ of heat from $91 \mathrm{~kg} / \mathrm{hr}$ water flow, $10^{\circ} \mathrm{C}$ outlet water temperature, volume of $2048 \mathrm{~cm}^{3}\left(125 \mathrm{in}^{3}\right)$ or less, and mass of $1.59 \mathrm{~kg}(3.4 \mathrm{lbm})$ or less while operating in a vacuum of $10^{-12}$ torr. Another objective was to explore and address manufacturing issues associated with a compact, lightweight SWME design. Finally, the new SWME prototype will also serve as a test bed for exploring other issues such as membrane contamination.

To date, work on the new SWME prototype has included performing conceptual design trade studies, deriving applicable design requirements, detailed design of the selected configuration, and preliminary investigations of manufacturing issues. Conceptual designs, classified by their water channel layout, were either of the concentric annuli configuration or 
parallel rectangular configuration. While a simple spreadsheet thermal math model was developed for both basic configurations, this paper presents only the concentric circular annuli thermal-hydraulic model. Analysis of the thermal analysis results illustrates the effect geometric parameters have on the SWME heat rejection and constraining design parameters. Finally, a design down-select analysis is also presented covering such concerns as parts count, mass, volume and manufacturing.

\section{OVERVIEW OF THE SHEET MEMBRANE SWME}

A clarification pertaining to nomenclature is necessary before continuing. First, the use of "water" will always imply water in the liquid form while vapor will always refer to water in the gas phase. This type of SWME is often called a sheet membrane SWME or sheet SWME in reference to the very thin $(\sim 25 \mu \mathrm{m})$ hydrophobic, porous Teflon ${ }^{\circledR}$ membrane, which looks and feels like a sheet of cloth.

The sheet membrane SWME is a relatively simple device consisting of the membrane subassemblies that form the water and vapor channels, water inlet and outlet headers, and backpressure valve (see Figure 1). As water flows through the water channel, a very small amount evaporates through the membrane, thus cooling the flowing water. This vapor flows through the backpressure valve to the vacuum. The backpressure valve controls the vapor atmospheric pressure, which is one variable that affects evaporation rate. The evaporation rate is also a function of the membrane temperature, which in turn is a function of water temperature, water mass flow, and convection heat transfer coefficient.

Figure 2 illustrates the alternating pattern of vapor and water channels as well as the membrane sub-assemblies. Figure 2 also illustrates the screens that provide structural support to the sheet membranes and help shape the water channel. The screens prevent evaporation where contact is made with the membrane. An ideal screen is one in which the screen structure is minimized thus maximizing the screen open area. Finally, comparing Figures 1 and 2 show that the water channel shapes could vary as needed to meet the intended goals.

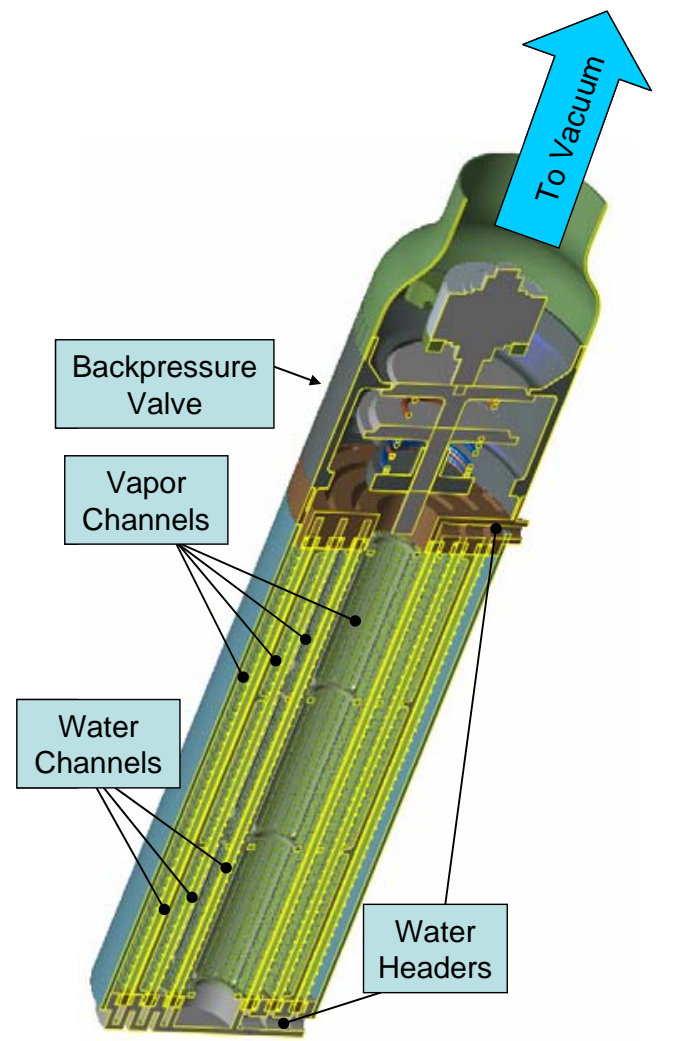

Figure 1 Overview of a Concentric Annuli Sheet Membrane SWME

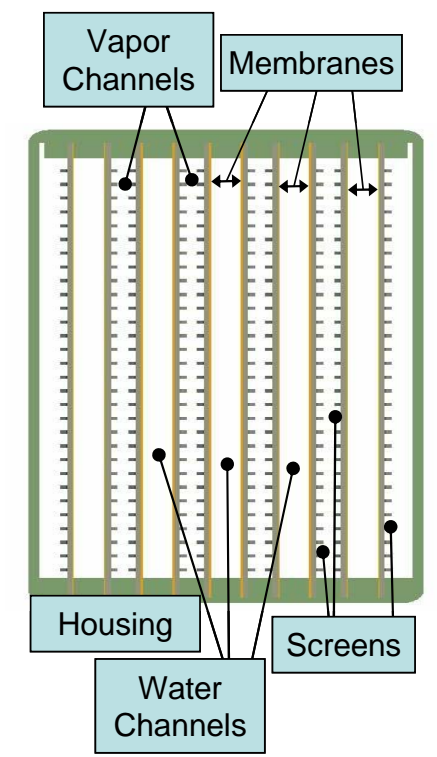

Figure 2 Cross-sectional View of a Stacked Rectangular Channel Sheet Membrane SWME 


\section{SIMPLIFIED MATH MODELING OF THE SHEET SWME TO PERFORM DESIGN TRADES}

A key reason for modeling the SWME simply was to develop a tool for SWME mechanical designers to quickly understand the impact of geometric changes as they tried to meet a myriad of packaging constraints. The pivot table feature of Microsoft Excel generate plots that permits variables to be set via dropdown menus was used to achieve this goal. Preliminary hand calculations showed that meeting the volume goal would require the SWME to have multiple parallel water loop and water vapor passages, thus increasing the number of adjustable parameters.

Initial interest focused on a concentric annuli design due to the successful prototype [1] and likewise developing the corresponding math model developed first. Only the concentric annuli sheet membrane math model is presented in this paper. Most of what is presented is applicable to the other configurations.

\section{Concentric Annuli Configuration Flow Regimes}

A key question pertaining to the concentric annuli configuration was how to balance the water flow through all annuli such that uniform heat rejection is achieved across all membrane surfaces. Ideally, the total water mass flow would be distributed in a manner resulting in equal Reynolds number and thermal length for each annulus. Assuming constant property laminar flow, a likely flow regime due to the low total mass flow rate of $91 \mathrm{~kg} / \mathrm{hr}$, and neglecting pressure drops associated with the inlet and outlet headers permitted an analysis that provided insight into the question of flow distribution. Given that the pressure drop from the inlet header to the outlet header is constant for a fixed total water flow and the laminar flow assumptions, the pressure drop of the laminar water flow through each annulus is equal to the following equation:

$$
\Delta \mathrm{P}=32 \mathrm{~L} \frac{\mu_{\mathrm{w}}}{\rho_{\mathrm{w}}} \frac{\dot{\mathrm{m}}_{\mathrm{w}, \mathrm{i}}}{\mathrm{D}_{\mathrm{h}, \mathrm{i}}^{2} \mathrm{~A}_{\mathrm{cs}, \mathrm{i}}}
$$

Rearranging equation 1 for $\mathrm{m}_{\mathrm{i}}$ and summing for all annuli yields the water flow pressure drop in terms of total water mass flow as shown in equation 2.

$$
\Delta \mathrm{P}=32 \mathrm{~L} \frac{\mu_{\mathrm{w}}}{\rho_{\mathrm{w}}} \frac{\dot{\mathrm{m}}_{\mathrm{w}, \text { Total }}}{\sum \mathrm{D}_{\mathrm{h}, \mathrm{i}}^{2} \mathrm{~A}_{\mathrm{cs}, \mathrm{i}}}
$$

Equations 1 and 2 yield an important relation (equation 3 ) between the total mass flow and mass flow through each annulus that is used in the calculation of the Reynolds number of a single annulus (equation 4).

$$
\begin{aligned}
& \frac{\dot{\mathrm{m}}_{\mathrm{w}, \mathrm{i}}}{\mathrm{A}_{\mathrm{cs}, \mathrm{i}}}=\frac{\dot{\mathrm{m}}_{\mathrm{w}, \mathrm{Total}} \mathrm{D}_{\mathrm{h}, \mathrm{i}}^{2}}{\sum \mathrm{D}_{\mathrm{h}, \mathrm{i}}^{2} \mathrm{~A}_{\mathrm{cs}, \mathrm{i}}} \\
& \operatorname{Re}_{\mathrm{i}}=\frac{\dot{\mathrm{m}}_{\mathrm{w}, \mathrm{i}} \mathrm{D}_{\mathrm{h}, \mathrm{i}}}{\mu \mathrm{A}_{\mathrm{cs}, \mathrm{i}}}=\frac{\dot{\mathrm{m}}_{\mathrm{w}, \text { Total }} \mathrm{D}_{\mathrm{h}, \mathrm{i}}^{3}}{\sum \mathrm{D}_{\mathrm{h}, \mathrm{i}}^{2} \mathrm{~A}_{\mathrm{cs}, \mathrm{i}}}
\end{aligned}
$$

If the annuli have equal hydraulic diameters, the total water flow will be distributed such that each annulus will have equal Reynolds numbers as shown by Equations 3 and 4 . This is easily achievable for a concentric annuli configuration because the annulus water channel hydraulic diameter is equal to twice the water channel gap $\left(D_{h}=2 t=2\left(r_{0}-r_{i}\right)\right)$. Consequently, concentric annuli SWME configurations considered had equal gaps for all annuli.

Understanding that equal annulus gaps yield equal Reynolds numbers for each annulus is important because it also leads to equal thermal performance for each annulus. Equal Reynolds number results in equal mean Nusselt numbers since the Nusselt number is a function of the thermal length, which is constant for laminar flow through concentric annuli channels with equal gap (see equation 5).

$$
\mathrm{x}^{+}=\frac{2 \mathrm{~L} / \mathrm{D}_{\mathrm{h}}}{\operatorname{Re} \operatorname{Pr}}
$$

Finally, equal annuli gaps simplify the thermal calculations due to the resulting uniform convection heat coefficient as shown in equation 6. A key assumption of equation 6 is that the 
Nusselt numbers for the inner and outer annulus walls are equal. This assumption is valid where the ratio of the annulus inner and outer wall diameters is close to one.

$$
\mathrm{h}_{\mathrm{m}, \mathrm{i}}=\mathrm{h}_{\mathrm{m}}=\frac{\mathrm{Nu}_{\mathrm{m}} \mathrm{k}}{\mathrm{D}_{\mathrm{h}}}
$$

\section{Derivation of SWME Total Heat Rejection}

The SWME heat transfer problem consists of convection heat transfer in balance with evaporative heat transfer assuming steady state operation. Three equations for the SWME total heat rejection result from this balance and are presented in equation 7 . Note the energy balance of the loop water flow neglects the energy carried away by the mass of water evaporated. At design conditions, the mass flow of evaporated water is about 1 percent of the 91 $\mathrm{kg} / \mathrm{hr}$ loop flow.

$$
\begin{aligned}
& \mathrm{q}=\mathrm{f}_{\text {void }} A_{\text {mem }} h_{m}\left(\bar{T}_{w}-T_{\text {mem }}\right) \\
& \mathrm{q}=\mathrm{f}_{\text {void }} A_{\text {mem }} G_{v} h_{l g} \\
& q=\dot{m}_{w, \text { Total }} C_{p}\left(T_{w, \text { in }}-T_{w, \text { out }}\right)
\end{aligned}
$$

The key to solving this heat balance is knowing that the membrane water vapor mass flux, $G_{v}$, is a function of the membrane temperature. Because of the form of $G_{v}$, an analytical solution for the membrane temperature was not feasible. Hence, the membrane temperature was iterated upon using equation 8, which was derived from the three forms of the SWME heat rejection in equation 7. Equation 8 was derived assuming the average water temperature, $\overline{\mathrm{T}}_{\mathrm{w}}$, and average membrane temperature, $\mathrm{T}_{\mathrm{mem}}$, are equal to arithmetic averages of respective values at the inlet and outlet. Prior finite difference modeling results of an annulus SWME showed this to be a reasonable assumption.

$$
\mathrm{T}_{\text {mem }}=\mathrm{T}_{\mathrm{w}, \text { in }}-\mathrm{G}_{\mathrm{v}} \mathrm{h}_{\mathrm{lg}}\left(\frac{\mathrm{f}_{\text {void }} \mathrm{A}_{\mathrm{mem}}}{2 \dot{\mathrm{m}}_{\mathrm{T}} \mathrm{C}_{\mathrm{P}}}+\frac{1}{\mathrm{~h}_{\mathrm{m}}}\right) \text { (8) }
$$

What makes this SWME design trade study feasible is the previous work characterizing the water vapor mass flow through the Teflon $\AA$ membrane. The test correlated version of the membrane water vapor mass flux equation, which differs from theory only by a factor of 0.85 [1], was used in this trade study and is presented in equation 9 with the constants, $C_{1}$ and $C_{2}$, defined in equation 10 .

$$
\begin{gathered}
\mathrm{G}_{\mathrm{v}}=\mathrm{C}_{1}\left(\mathrm{P}_{\mathrm{H} 2 \mathrm{O}, \mathrm{sat}}\left(\mathrm{T}_{\text {mem }}\right)-\mathrm{P}_{\text {SWME-vap }}\right) \sqrt{\frac{\mathrm{C}_{2}}{\mathrm{~T}_{\text {mem }}}} \\
\mathrm{C}_{1}=0.85 \bullet 0.83 \frac{\mathrm{d}_{\text {pore }}}{3 \mathrm{~L}_{\text {pore }}} \\
\mathrm{C}_{2}=\frac{8}{\pi \mathrm{R}_{\mathrm{H} 2 \mathrm{O}}}
\end{gathered}
$$

For deep space applications, the amount of water that can evaporate through the membrane is also a function of the atmospheric pressure of the water vapor on the vapor side of the membrane. While iterating upon the membrane temperature, the membrane vapor side atmospheric pressure was simultaneously iterated upon. Pressure drop calculations from the vapor channel to deep space vacuum included flow through the vapor channel and backpressure valve, which were assumed continuum laminar flow and orifice choked sonic flow, respectively (see Equation 11). Equation 12 presents the assumptions regarding vapor property calculations.

$$
\begin{aligned}
& \mathrm{P}_{\text {SWME-vap }}=\Delta \mathrm{P}_{\text {vap }}+\mathrm{P}_{\mathrm{BPV} \text {,up }} \\
& \Delta \mathrm{P}_{\text {vap }}=\frac{32 \mathrm{~L} \mu_{\text {vap }}}{3 \rho_{\text {vap }}} \frac{\dot{\mathrm{m}}_{\text {vap, Total }}}{\sum \mathrm{D}_{\mathrm{h}, \text { vap }, \mathrm{i}}^{2} \mathrm{~A}_{\text {cs, vap }, \mathrm{i}}} \\
& \mathrm{P}_{\mathrm{BPV}, \text { up }}=\frac{\dot{\mathrm{m}}_{\mathrm{T}, \text { vap }} \sqrt{\mathrm{T}_{\text {vap }, \text { up }}}}{\mathrm{A}_{\mathrm{BPV}} \sqrt{\frac{\gamma}{\mathrm{R}_{\mathrm{H} 2 \mathrm{O}}}\left(\frac{2}{\gamma+1}\right)^{\frac{\gamma+1}{\gamma-1}}}}
\end{aligned}
$$




$$
\begin{aligned}
& \rho_{\text {vap }}=\frac{P_{\text {SWME-vap }}}{R_{\text {H2O }} T_{\text {mem }}} \\
& T_{\text {vap,up }}=T_{\text {mem }}
\end{aligned}
$$

\section{TRADE STUDY PARAMETERS}

So that the mechanical designer could choose values resulting in a compact design, an Excel spreadsheet was set up to calculate the SWME maximum heat rejection verses the following seven geometric variables:

1) number of annulus water channels, $n_{w}$ - $\mathrm{n}_{\mathrm{w}}=2,3,4,5$

2) water channel gap, $t_{w}$ - $\mathrm{t}_{\mathrm{w}}=1,2,4 \mathrm{~mm}$

3) vapor channel gap, tvap

- $\mathrm{t}_{\mathrm{vap}}=2,4,6 \mathrm{~mm}$

4) water channel length, $L$

- $\mathrm{L}=150,175,200 \mathrm{~mm}$

5) core diameter, $D_{c}$

- $\mathrm{D}_{\mathrm{c}}=25,50,75 \mathrm{~mm}$

6) void fraction, $f_{\text {void }}$

- $\mathrm{f}_{\mathrm{void}}=0.65,0.75,0.85$

7) backpressure valve orifice diameter, $D_{B P V}$

- $\mathrm{D}_{\mathrm{BPV}}=25,50,75 \mathrm{~mm}$

The core diameter is the diameter of the innermost membrane. The void fraction equals the membrane support wire screen open area divided by the total geometric area. The other variables are self explanatory.

For all cases, the water mass flow and inlet temperature were set equal to $91 \mathrm{~kg} / \mathrm{hr}$ and $291 \mathrm{~K}$, respectively. The $291 \mathrm{~K}$ water inlet temperature was derived from the $810 \mathrm{~W}$ heat rejection, $91 \mathrm{~kg} / \mathrm{hr}$ water flowrate, and $10^{\circ} \mathrm{C}$ water outlet requirements. Finally, the convection heat transfer coefficient for all cases was based on a mean Nusselt number equal to 8.235 and the thermal conductivity of water at $15^{\circ} \mathrm{C}$. This Nusselt number corresponds to fully developed laminar flow through an annulus with constant heat flux wall boundary conditions and a ratio of inner to outer diameters equal to 1 . On average this assumption works well for this trade study even for the annuli with ratios significantly less than one. For example, steady state constant heat flux wall Nusselt numbers of the worst case annulus with inner and outer diameters of $25 \mathrm{~mm}$ and $29 \mathrm{~mm}$, respectively equal 9.316 and 7.475 [2] averaging 8.4, which is 2 percent greater than the assumed 8.235 Nusselt number.

\section{ANNULUS SWME DESIGN PARAMETRIC ANALYSIS RESULTS}

Ten iterations were performed for each case with analysis of the results showing good convergence. On average, the membrane temperature converged to within $+/-0.02^{\circ} \mathrm{C}$ and the evaporated water mass flow converged to within the final value $+/-0.2$ percent. Reynolds numbers ranged from 23 to 240 demonstrating that all cases were in the laminar flow regime. Non-dimensional thermal lengths ranged from 0.02 to 0.9 with the average equal to 0.1 . In the cases where the thermal length was less than 0.1 the assumed, fully developed flow Nusselt number of 8.235 under predicted the SWME heat rejection. However, laminar flow theory indicates the under prediction would be around $7 \%$ [2], which is acceptable given the purpose of the trade study. Finally, maximum water pressure drop was 257 Pascals remaining well below the SWME goal of 6894 Pascals (1 psid).

The original hopes for a membrane support screen with a high void fraction proved overly optimistic and, simultaneously, designers quickly understood the beneficial mass effects of reducing the overall SWME diameter. Consequently, the 0.65 void fraction and $25 \mathrm{~mm}$ core diameter cases are the only ones presented in this section. Figure 3 summarizes the results showing that no two concentric annulus water channel configuration reached the $810 \mathrm{~W}$ goal and that increasing the number of channels always resulted in greater performance. This latter effect results from adding two more membrane surfaces with a larger diameter. However, the goal of minimizing the overall diameter necessitates minimizing the number of water channels.

Figure 3 also shows that, as expected, increasing the water channel gap decreased the SWME heat rejection. This characteristic led to the decision to limit consideration to water channel gaps $2 \mathrm{~mm}$ or greater to minimize the impact of manufacturing tolerances. Analysis of the $150 \mathrm{~mm}, 3$ water channel configurations results illustrate this sensitivity showing that changing the gap from $1 \mathrm{~mm}$ to $2 \mathrm{~mm}$ caused an $85 \mathrm{~W}$ reduction of heat rejection whereas a gap 
change from 2 to $4 \mathrm{~mm}$ caused only a $66 \mathrm{~W}$ heat rejection reduction.

With these constraints, Figure 3 shows that the only 3 water channel configurations meeting the $810 \mathrm{~W}$ heat rejection requirement is the $200 \mathrm{~mm}$ length, $2 \mathrm{~mm}$ water channel gap one. Predicted total heat rejection for this configuration was $900 \mathrm{~W}$.

The predicted membrane temperature must be considered because of the potential for freezing the membrane. Figure 4 plots membrane temperature predictions showing that the water channel gap and number of water channels have a significant impact on membrane temperatures. Average membrane temperatures for the 3 water channels, $200 \mathrm{~mm}$ length, 4, 2, and $1 \mathrm{~mm}$ channel gap cases were $3.0^{\circ} \mathrm{C}, \quad 6.4^{\circ} \mathrm{C}$, and $8.8^{\circ} \mathrm{C}$, respectively. In contrast to manufacturing tolerance concerns, membrane temperatures benefit from reducing the water channel gap.

The backpressure valve orifice diameter can also have an impact on predicted SWME heat rejections due to its effect on the membrane vapor side atmospheric pressure. Heat rejections for the 3 channel, $200 \mathrm{~mm}$ length, $2 \mathrm{~mm}$ water channel gap, $25 \mathrm{~mm}$ core diameter configurations were $767 \mathrm{~W}, 900 \mathrm{~W}$, and $929 \mathrm{~W}$ with the $25 \mathrm{~mm}, 50 \mathrm{~mm}$, and $75 \mathrm{~mm}$ backpressure valve orifice diameters, respectively. Increasing the orifice from $50 \mathrm{~mm}$ to $75 \mathrm{~mm}$ showed diminishing improvement.

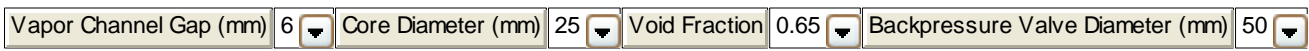

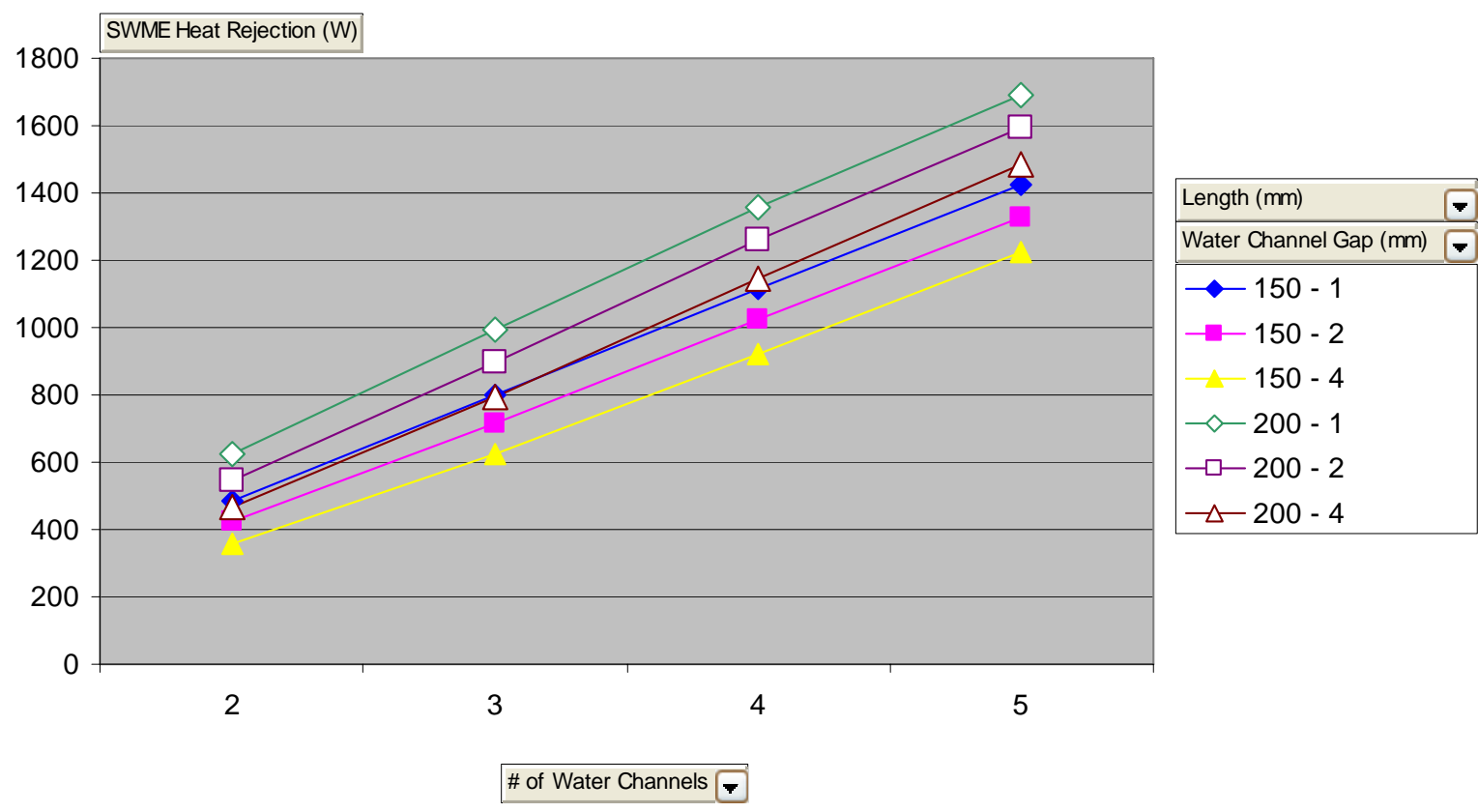

Figure 3 Predicted SWME Heat Rejection (W) as a Function of Number of Annulus Water Channels, Water Channel Gap $(\mathrm{mm})$, and Water Channel Length $(\mathrm{mm}) ; \mathrm{t}_{\text {vap }}=6 \mathrm{~mm}, \mathrm{D}_{\mathrm{c}}=25 \mathrm{~mm}, \mathrm{f}_{\mathrm{void}}=0.65, \mathrm{D}_{\mathrm{BPV}}=$ $50 \mathrm{~mm}$ 
\begin{tabular}{|l|l|l|l|l|l|l|l|l|l|l|}
\hline Vapor Channel Gap $(\mathrm{mm})$ & 6 & Core Diameter $(\mathrm{mm})$ & 25 & Void Fraction & 0.65 & - & Backpressure Valve Diameter $(\mathrm{mm})$ & 50
\end{tabular}

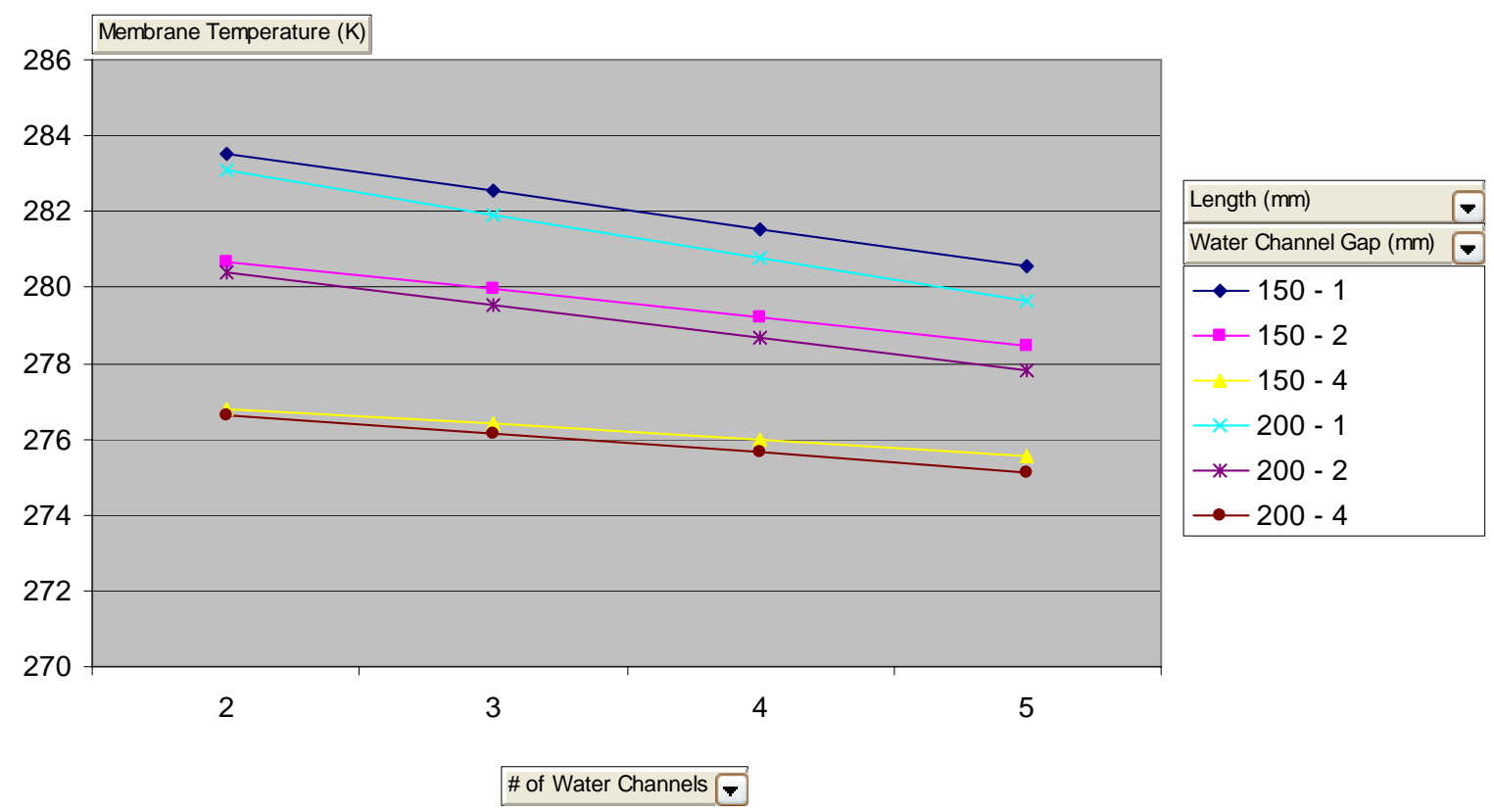

Figure 4 Average Membrane Temperatures (K) as a Function of Number of Annulus Water Channels, Water Channel Gap $(\mathrm{mm})$, and Water Channel Length $(\mathrm{mm}) ; \mathrm{t}_{\mathrm{vap}}=6 \mathrm{~mm}, \mathrm{D}_{\mathrm{c}}=25 \mathrm{~mm}, \mathrm{f}_{\text {void }}=0.65, \mathrm{D}_{\mathrm{BPV}}=$ $50 \mathrm{~mm}$

\section{SHEET MEMBRANE SWME DOWN SELECT ANAYLYSIS}

Required membrane surface area for eight conceptual configurations were calculated and preliminary designs were then developed using the Pro-Engineering computer aided design software. From the design data, mass, volumes, and overall dimensions were obtained and are listed in Table 1. In addition to design data, Table 1 also lists metrics such as ease of manufacturing by which the conceptual configurations were judged.

The three concentric circular annuli design immediately stands out immediately due to having the lowest mass of $1.8 \mathrm{lbm}$ as well as the lowest volume of $58 \mathrm{in}^{3}$. The next best candidate based on volume was the four concentric circular annuli design. However, the addition of another annulus increases the manufacturing complexity as well as the number of required sealed surfaces. Reducing the number of sealed surfaces is desirable so that the potential for leaks is minimized. On a mass scale, the next best concepts are the four concentric square annuli and star-shaped single annulus concepts. Of the two, the star-shaped single annulus concept has the larger volume. The attractiveness of the star-shaped annulus concept is the low part count and low number of required seals. However, its manufacturability is considered to be complex and difficult. Minimizing the number of sealed surfaces were also the objective of the folded membrane concepts. These, however, incurred high masses. Finally, none of the stacked, rectangular or corrugated configurations faired well due to relatively high mass, part count, and number of sealed surfaces. 
Table 1 Sheet Membrane SWME Design Down Select Criteria and Data

\begin{tabular}{|c|c|c|c|c|c|c|c|c|c|c|c|c|c|c|c|}
\hline Concept & $\begin{array}{l}\text { Body } \\
\text { Mass } \\
\text { (lbs) }\end{array}$ & $\begin{array}{c}\text { Body } \\
\text { Length } \\
\text { (in) }\end{array}$ & $\begin{array}{c}\text { Body } \\
\text { Width } \\
\text { (in) }\end{array}$ & $\begin{array}{l}\text { Body } \\
\text { Height } \\
\text { (in) }\end{array}$ & $\begin{array}{c}\text { Body } \\
\text { Volume } \\
\text { (in^3) }\end{array}$ & $\begin{array}{l}\text { Number } \\
\text { of Water } \\
\text { Channels }\end{array}$ & $\begin{array}{c}\begin{array}{c}\text { Number } \\
\text { of } \\
\text { Sealing } \\
\text { Surfaces }\end{array} \\
\end{array}$ & $\begin{array}{c}\text { Part } \\
\text { Count }\end{array}$ & $\begin{array}{c}\text { Mass/Area } \\
\text { Ratio } \\
\left(\mathrm{lbs} / \mathrm{in}^{2}\right)\end{array}$ & $\begin{array}{c}\text { Ease of } \\
\text { Manufacture }\end{array}$ & $\begin{array}{c}\text { Safety } \\
\text { Margin }\end{array}$ & Reliability & $\begin{array}{c}\text { Access for } \\
\text { Maintenance }\end{array}$ & Cost & Robust \\
\hline $\begin{array}{l}3 \text { Concentric } \\
\text { Circular } \\
\text { Annuli } \\
\end{array}$ & 1.83 & 8.00 & Dia & 3.05 & 58.4 & 3 & 18 & 16 & 0.075 & Medium & High & High & Good & $\begin{array}{c}\text { Medium/ } \\
\text { Low }\end{array}$ & High \\
\hline $\begin{array}{l}4 \text { Concentric } \\
\text { Circular } \\
\text { Annuli } \\
\end{array}$ & 3.34 & 7.13 & Dia & 3.30 & 61.0 & 4 & 24 & 27 & 0.14 & $\begin{array}{c}\text { Medium/ } \\
\text { Hard }\end{array}$ & High & High & Good & $\begin{array}{c}\text { Medium/ } \\
\text { Low }\end{array}$ & High \\
\hline $\begin{array}{l}4 \text { Concentric } \\
\text { Square } \\
\text { Annuli } \\
\end{array}$ & 2.5 & 7.47 & 3.45 & 3.45 & 88.9 & 3 & 18 & 15 & 0.09 & Medium & High & High & Good & $\begin{array}{c}\text { Medium/ } \\
\text { Low }\end{array}$ & High \\
\hline $\begin{array}{l}\text { Stacked Flat } \\
\text { Panels }\end{array}$ & 7 & 8.75 & 4.47 & 2.25 & 88.0 & 5 & 40 & 24 & 0.36 & Hard & Medium & Medium & Good & $\begin{array}{c}\text { High/ } \\
\text { Medium }\end{array}$ & Medium \\
\hline \begin{tabular}{|l} 
Stacked \\
Vertically \\
Corrugated \\
Panel \\
\end{tabular} & 5.1 & 8.50 & 4.47 & 2.50 & 95.0 & 3 & 24 & 19 & 0.24 & Hard & Medium & Medium & Good & $\begin{array}{c}\text { High/ } \\
\text { Medium }\end{array}$ & Medium \\
\hline \begin{tabular}{|l} 
Stacked \\
Horizontally \\
Corrugated \\
Panel \\
\end{tabular} & 5.57 & 8.50 & 4.74 & 2.16 & 87.0 & 4 & 32 & 19 & 0.3 & Hard & Medium & High & Good & $\begin{array}{c}\text { High/ } \\
\text { Medium }\end{array}$ & High \\
\hline $\begin{array}{l}\text { Concentric } \\
\text { Star Pattern }\end{array}$ & 2.42 & 8.00 & Dia & 4.00 & 100.5 & 1 & 6 & 8 & 0.075 & Medium & High & High & Good & $\begin{array}{c}\text { Medium/ } \\
\text { Low }\end{array}$ & High \\
\hline $\begin{array}{l}3 \text { Folded } \\
\text { Membrane } \\
\end{array}$ & 4.2 & 9.50 & 2.50 & 5.30 & 126.0 & 1 & 4 & 7 & 0.18 & Medium & High & High & Good & $\begin{array}{c}\text { Medium/ } \\
\text { Low }\end{array}$ & High \\
\hline $\begin{array}{l}5 \text { Folded } \\
\text { Membrane - } \\
\text { ESTIMATED }\end{array}$ & 4.00 & 8.00 & 3.50 & 4.00 & 112.0 & 1 & 4 & 7 & 0.14 & Medium & High & High & Good & $\begin{array}{c}\text { Medium/ } \\
\text { Low }\end{array}$ & High \\
\hline $\begin{array}{l}\text { Color } \\
\text { Represents } \\
\text { Qualitative } \\
\text { Color } \\
\text { Represents } \\
\text { Calculated } \\
\end{array}$ & & & & & & & & & & & & & & & \\
\hline
\end{tabular}

\section{CONCLUSIONS \& FORWARD WORK}

Thermal-hydraulic performance and design/manufacturing trade studies were performed in support of an effort to advance the sheet Teflon ${ }^{\circledR}$ SWME technology by designing and building a compact, lightweight SWME. Using simplified thermal-hydraulic math models, multiple configurations including concentric annuli and parallel stacked channels configurations were sized to meet the SWME $810 \mathrm{~W}$ heat rejection and $10^{\circ} \mathrm{C}$ outlet water temperature requirements. Preliminary designs of each candidate configuration were then developed to determine total volume and mass. The preliminary designs were also used to helped evaluate manufacturing complexity. Results of these trades studies led to the decision to build a three concentric circular annuli water channel SWME. The $0.82 \mathrm{~kg}$ mass and $950 \mathrm{~cm}^{3}$ volume of this configuration were the lowest and met the $1.59 \mathrm{~kg}$ and $2048 \mathrm{~cm}^{3}$ requirements. The manufacturing complexity of this configuration was considered medium, which was on par with or better than the other configurations.
Work has started on the detailed designs with the goal of manufacturing the two test articles by Fall 2008. Planned testing will asses many important characteristics including thermalhydraulic performance and susceptibility to contamination.

\section{REFERENCES}

1. Ungar, E.K, and G. A Thomas, "Design and Testing of a Spacesuit Water Membrane Evaporator," Proceedings of the 2001 Nation Heat Transfer Conference, ASME, Anaheim, CA, June 2001.

2. Kays, W. M. and Crawford, M. E. Convective Heat and Mass Transfer. McGraw-Hill, Inc., New York, 1993. 


\section{LIST OF SYMBOLS}

Note: water refers to liquid water while vapor refers to water in the gas phase.

$A_{c s, I} \quad$ Selected water channel cross-sectional area

$A_{c s, v a p, I}$ Selected vapor channel cross-sectional area

$A_{B P V}$ Backpressure valve fully open orifice area

$A_{\text {mem }}$ Total membrane area

$\mathrm{C}_{\mathrm{p}} \quad$ Water specific heat

$\mathrm{d}_{\text {pore }} \quad$ Membrane pore diameter $=0.1 \mu \mathrm{m}$

$D_{\mathrm{BPV}}$ Backpressure valve orifice diameter

$D_{c}$ Diameter of innermost membrane cylinder

$\mathrm{D}_{\mathrm{h}} \quad$ Hydraulic diameter

$D_{h, I} \quad$ Hydraulic diameter of water channel $i$

$D_{h, v a p, I}$ Hydraulic diameter of vapor channel i

$f_{\text {void }}$ Screen open area as fraction of total area

$\mathrm{G}_{\mathrm{V}} \quad$ Vapor mass flux through membrane

$h_{\text {lg }} \quad$ Water latent heat of vaporization

$\mathrm{h}_{\mathrm{m}} \quad$ Water mean heat transfer coefficient

$h_{m, i} \quad$ Water mean heat transfer coefficient of channel i

k thermal conductivity

$\mathrm{L} \quad$ Water and vapor channel length

$L_{\text {pore }}$ Membrane thickness $=25 \mu \mathrm{m}$

$\dot{\mathrm{m}}_{\mathrm{w}, \mathrm{i}} \quad$ Water mass flow through channel i

-

$\mathrm{m}_{\mathrm{w} \text {,Total }}$ Total water mass flow through SWME neglecting water evaporated

$\dot{m}_{\text {vap,Total }}$ Total vapor mass flow $=f_{\text {void }} A_{\text {mem }} G_{v}$

$\mathrm{n}_{\mathrm{w}} \quad$ Number of water channels

$\mathrm{Nu}_{\mathrm{m}} \quad$ Mean Nusselt number

$\mathrm{P}_{\mathrm{H} 2 \mathrm{O} \text {,sat }}$ Saturation pressure of water

$P_{\text {SWME-vap Atmospheric pressure on vapor side }}$ of membrane

$\mathrm{P}_{\mathrm{BPV} \text {,up Atmospheric pressure upstream of }}$ backpressure valve orifice

$\mathrm{Pr} \quad$ Prandtl number

$\Delta \mathrm{P} \quad$ Water channel pressure drop

$\Delta P_{\text {vap }}$ Vapor channel pressure drop

q SWME heat rejection

$\mathrm{R}_{\mathrm{H} 2 \mathrm{O}}$ Water vapor gas constant

$\mathrm{Re} \quad$ Reynolds number

$\mathrm{Re}_{\mathrm{i}} \quad$ Reynolds number of channel $\mathrm{i}$

$t_{w} \quad$ Water annuli channel gap

$t_{\text {vap }} \quad$ Vapor annuli channel gap
$T_{\text {mem }}$ Membrane average temperature

$T_{\text {vap,up }}$ Temperature of vapor upstream of backpressure valve orifice

$\mathrm{T}_{\mathrm{W}, \text { in }} \quad$ SWME inlet water temperature

$T_{w, i n} \quad$ SWME outlet water temperature

$\mu_{\mathrm{w}} \quad$ Liquid water dynamic viscosity

$\mu_{\text {vap }} \quad$ Water vapor dynamic viscosity

$\rho_{w} \quad$ Liquid water density

$\rho_{\text {vap }} \quad$ Water vapor density 